\title{
JACOTOT O EL DESAFÍO DE UNA ESCUELA DE IGUALES
}

\author{
INÉS DUSSEL
}

\begin{abstract}
RESUMEN: El libro de Rancière es un texto provocador para los pedagogos. A través de la historia del maestro Jacotot, que dice que puede enseñarse sin saber, se despliega un tratado sobre la igualdad, tejido a través de la crítica a las relaciones pedagógicas que construyó la modernidad. La critica tiene dos líneas: por un lado, la educación escolar y profesoral es vista como embrutecimiento, en contra del mito pedagógico que siempre se creyó igualitario y emancipador; y por otro, se cuestiona la figura del intelectual crítico como reproductor de la misma desigualdad que critica. La intervención de Rancière es bienvenida en un debate educativo crecientemente despolitizado, virado a las didácticas tecnocráticas, y donde las urgencias del hambre y la violencia dificultan pensar en otras proyecciones politico-educativas.

Palabras clave: Rancière. Pedagogía. Igualdad. Intelectual crítico. Jacotot.
\end{abstract}

\section{JACOTOT OR THE CHALLENGE OF A SCHOOL OF EQUALS}

ABSTRACT: The ignorant schoolmaster, by Rancière, is a provocation to any educator. Through the story of Jacotot, a schoolmaster who claimed that no knowledge is needed to teach, Rancière wrote a treatise on equality based on a critique of the pedagogical relationships produced by modernity. His critique is twofold: on the one hand, in contrast with the pedagogical myth that always thought of itself as emancipating and egalitarian, he describes the teacher and professor education as stultifying. On the other, he sees the critical intellectuals as reproducers of the very inequality they criticize. This intervention of Rancière is welcome in an educational debate less and less politicized, dominated by technocratic

Directora del Área Educación de FLACSO, Argentina. E-mail: idussel@fracso.org.ar

Educ. Soc., Campinas, vol. 24, n. 82, p. 213-219, abril 2003

Disponível em <http://www.cedes.unicamp.br> 
pedagogies, and where the urgency of hunger and violence makes it difficult to think about renewing the educational policies.

Key words: Rancière. Pedagogy. Equality. Critical intellectual. Jacotot.

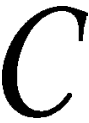

omentar el texto de Rancière es una tarea ardua para una educadora que está contenta de serlo. Ya desde sus primeras páginas, $E l$ maestro ignorante provoca incomodidad a cualquiera formado en la tradición pedagógica y comprometido con alguna forma de transmisión de saberes, más o menos escolar o académica. El ensayo (o más bien fábula, como la llama su traductora al inglés, Kristin Ross) que el filósofo Jacques Rancière escribió sobre la aventura educativa de Joseph Jacotot a principios del siglo XIX, cuestiona todos los presupuestos sobre los que se basa la razón pedagógica moderna. Jacotot dice, para horror de los pedagogos: no hace falta saber para enseñar.

Una se pregunta qué anduvo diciendo y escribiendo todos estos años. Imagina también la cara de espanto de quienes lean el libro en las facultades de educación. Pero hay más, porque la herejía de Jacotot sigue. No quiere educar a sus alumnos para que sean académicos que buscan la verdad; lo que vale es que sean sujetos libres, con una inteligencia emancipada, que no se sienta inferior a ninguna. No hay un saber mejor que otro: no importa que el maestro no sepa matemática o pintura, sólo es necesaria la voluntad de emancipar a los sujetos para enseñarles a ser libres, que puede aprenderse por la matemática, la pintura o la literatura, o cualquier otro saber. Jacotot denuncia: el profesor, defensor del orden de saberes y poderes actual, es un embrutecedor de inteligencias, porque sólo busca garantizar su superioridad subordinando la inteligencia y capacidades de los otros. El maestro ignorante, al contrario, al no tener el "saber sabio" del profesor, al suponer a sus alumnos como iguales, puede enseñarle a los otros a usar sus propios saberes, esto es, a desarrollar sus capacidades de comparación, de contrastación, de argumentación. Puede enseñarle al alumno, niño o adulto, rico o pobre, hombre o mujer, que él o ella puede aprender si trabaja y se dedica, si pone su voluntad en juego. Porque, para Jacotot, todos tenemos la misma capacidad de inteligencia; es la voluntad la que la subordina, la que la distrae, la que la sujeta.

Pero, ¿quién es este Jacotot que Rancière redescubre ahora? Como tantas otras biografías de la época, su historia lo lleva adonde va la revolución. Profesor de retórica en 1789, Jacotot se suma a la 
rebelión y se convierte en artillero, militar, secretario del ministro de Guerra, profesor de matemática, ideología, lenguas muertas y derecho, director de la Escuela Politécnica. Hacia el final de la era napoleónica, es elegido diputado de la convención, y debe exiliarse con la restauración borbónica de 1815 . Y es en su estancia en los Países Bajos que Jacotot "descubre", por accidente, un método de enseñanza que permite, dice él, la emancipación intelectual, cuando empieza a enseñar francés sin saber nada de cómo enseñarlo y, peor aún, sin saber una palabra de flamenco para hablar con sus estudiantes. Usa al Telémaco de Fénelon, porque consigue una edición bilingüe que permite comparar palabra por palabra ambos idiomas; $\mathrm{y}$ les dice a sus alumnos que lo estudien, que comparen, que verifiquen, que compongan lo que entienden. Sus alumnos lo sorprenden escribiendo en francés. Jacotot dice: podría haber sido cualquier texto. Podría haber sido cualquier enseñanza. Lo que importó fue mi voluntad de enseñarles, de que podían aprender. Los consideré como iguales, y aprendieron. Jacotot llama a su método la enseñanza universal, edita libros sobre la enseñanza de la lengua materna, la lengua extranjera, la música y la matemática, ${ }^{1}$ entre otros, y funda una revista, el Journal de l'émancipation intellectuelle. Tiene discípulos, escribe libros, y hasta dirige una escuela militar. Pero sabe que la emancipación es tarea de un hombre con otro hombre (así, en masculino), y que las instituciones sociales no toleran bien a los hombres libres.

Jacotot es interesante porque fue testigo de cómo se gestaron y cómo sucumbieron los ideales igualitarios de 1789 , y a pesar de eso siguió sosteniéndolos. Dice Rancière sobre Jacotot:

su locura fue haber percibido (...) (que el suyo) era el momento en que la joven causa de la emancipación, la de la igualdad de los hombres, era transformada en la causa del progreso social. ...... Jacotot fue el único igualitario que percibió la representación e institucionalización del progreso como un renunciamiento de la aventura moral e intelectual de la igualdad, y a la instrucción pública como lo que quedó del duelo de la emancipación. (1991/2002, p. 184)

Jacotot asiste a esta nueva configuración de los saberes y los poderes que desembocarán en la escuela pública obligatoria, en la universidad estatal, en la pedagogía ilustrada. Y tiene bien en claro las jerarquías que instauran, las exclusiones que las fundan, las injusticias que causan. 
Vale la pena dejarse inquietar por este texto provocador. La fábula de Jacotot, contada por Rancière, es un impresionante tratado sobre la igualdad, tejido a través de la crítica a las relaciones pedagógicas que construyó la modernidad. Ese primer anudamiento entre educación y desigualdad pega duro al corazón del mito pedagógico, que siempre se creyó igualitario. Plantear que la educación ha servido para embrutecer y eternizar las desigualdades es ir contra dos siglos y medio, al menos, de políticas y reflexiones pedagógicas que sostuvieron estar haciendo lo contrario. Pero es precisamente la radicalidad de su crítica lo que permite al texto de Rancière volver a colocar en el centro de las preocupaciones la cuestión de la igualdad. Una igualdad que, en el debate educativo latinoamericano, está acorralada por hambres urgentes que dicen que sólo hay que ocuparse de dar de comer, y por la amenaza de muertes prematuras, siempre violentas, que sobrevuela las escuelas, cuyo dramatismo dificulta pensar en otros plazos, otras construcciones, otras políticas. Una igualdad que también está borroneada por las retóricas de la equidad y la educabilidad que pululan en los discursos educativos, que sacaron hace rato de sus presupuestos la posibilidad de considerar a los pobres, los marginales o los perdedores como iguales y se conforman, en el mejor de los casos, con gerenciar la crisis y silenciar los conflictos. Aunque no tuviera más méritos que ése, el ensayo de Rancière ya haría un aporte fundamental al recolocar a la igualdad en el centro del debate pedagógico contemporáneo.

El segundo anudamiento entre educación y desigualdad que plantea Rancière pasa por la figura del intelectual crítico, del intelectual emancipador, que en la Francia de 1820 y 1830 estaba representado por los Boutmy, de Giradin o Saint-Simon, y en la Francia de 1980 en la que escribe Rancière por Althusser y Bourdieu. Este anudamiento también es inquietante para quien se reconoce heredera de las tradiciones críticas. El profesor que se anuncia como emancipador de las mentes, dicen Jacotot-Rancière, está reproduciendo la misma jerarquía desigual de saberes y poderes; sigue sin renunciar a ubicarse en el escalón superior de las inteligencias, señalando el conocimiento y el método verdaderos, despreciando la inteligencia de los otros. El intelectual crítico no desmantela las jerarquías; antes bien, las consagra, aunque sea por medio de la condena y la crítica. $\mathrm{Al}$ denunciar que los pobres y marginales son privados del único conocimiento que vale, que es el que él detenta, eterniza la desigualdad y la división del trabajo que garantiza su lugar de privilegio. 
Lo interesante, a nuestro juicio, de la postura de Rancière es que no se deja tentar por el populismo, por poner arriba a quien estaba abajo en la jerarquía y viceversa. Busca desarticular esa relación políticopedagógica no invirtiéndola sino construyendo otra, con el predominio de la política y la voluntad por sobre el saber sabio. No está claro qué saberes portará ese intelectual, si será político, filósofo, o poeta. En otra sección, Rancière dice que la comunidad de iguales será una sociedad de artistas, porque los artistas hacen, hablan de lo que hacen, y transforman sus obras en formas de demostrar que la humanidad está en ellos tanto como en otros (idem, ibid, p. 104 ss.). Es esta base igualitaria y este "hacer" lo que seduce a Rancière como proto-ordenamiento de los saberes y los poderes.

Hay que señalar que Rancière construye su texto de una manera extraña. No siempre resulta fácil distinguir quién habla, y eso también lo hace atractivo y desafiante. Rancière teje sus palabras en las frases de Jacotot, a quien llama, a veces él, a veces sus fuentes, el Fundador, el Maestro. Es un monólogo a dos voces, una voz con eco, un texto que habla con el pasado, con la herencia de la revolución de 1789, y con la Francia que sigue a 1968, con las pedagogías progresistas y críticas, con el poder estudiantil y el poder profesoral. En esa confusión de voces, pareciera a veces que no importa si Jacotot existió o no, si las conmovedoras frases del Journal de l'émancipation intellectuelle fueron alguna vez publicadas; al final de cuentas, como el Telémaco de Fénelon, el libro es una excusa para incitarnos a pensar, a contrastar, a construir un sentido.

Jacotot dijo que la enseñanza universal no iba a triunfar, pero tampoco iba a perecer. No podía hacer escuela, pero seguiría escuchándose. Quiso poner en su epitafio: "Creo que Dios creó al alma humana capaz de enseñarse a sí misma, y sin un maestro.” (Idem, ibid, p. 190). Jacotot fue el Maestro que no era maestro, o que no quería serlo; el maestro que no quería fundar una escuela. Pero ¿puede haber una enseñanza sin maestro? Y también, ¿puede haber un maestro sin escuela? Rancière parece responder la primera pregunta negativamente: no hay enseñanza sin maestro, aunque la enseñanza de ese maestro sea distinta a la didáctica o la pedagogía que estamos acostumbrados a ver, y tenga más que ver con transmitir una voluntad, una posibilidad, una confianza en que el otro es un igual y puede llegar por sí solo adonde yo, el maestro, he llegado. Los artesanos flamencos que aprendieron el francés podían aprender solos, pero fue la acción de Jacotot de decirles que eran capaces de aprenderlo la que 
les abrió el camino. La igualdad fue un punto de partida y no es un punto de llegada, y ese acto de igualarlos fue producido por un maestro. La segunda pregunta, para Rancière, tiene una respuesta taxativa: la escuela institucionaliza, ordena, subordina, y por lo tanto desmantela la emancipación intelectual que procuraba Jacotot. Se puede ser maestro sin escuela; más aún, se debe serlo, porque la única forma de mantener el ideal igualitario es resistir al formato escolar-académico que desiguala.

El tono taxativo, hasta esencialista ("la escuela es") de Rancière clausura la posibilidad de pensar en otras formas de escuela que produzcan otros efectos, formas que pueden estar en acción hoy o que merezcan ser creadas. Pero ése es también uno de sus grandes méritos: "la política es la práctica de afirmar la posición propia rompiendo la lógica del arché; esto es, la política es un evento iniciado por individuos o grupos que insisten que la configuración de un cierto ordenamiento político está equivocado." (Panagia, 2001, p. 1). Es esta denuncia de que hay un cálculo mal hecho, de que hay una injusticia que no se está escuchando, de que hay que volver a pensar sobre la justicia de ese orden, lo que define a la política, aún cuando no haya una solución propuesta. La intervención de Rancière es plenamente política, y es bienvenida en un debate educativo crecientemente despolitizado, dominado por las didácticas tecnocráticas. La obra de Rancière nos ayuda a pensar en nuestros alumnos como iguales, iguales no porque están inmersos en la misma situación desesperada y sin ley que nos horizontaliza sino porque tienen un lugar de pares en la sociedad más justa que queremos. Nos hace plantear que hay lugar para ellos en este mundo, no por un acto caritativo sino porque los creemos iguales, capaces, valiosos para nuestras vidas. Y aquí concluimos con Rancière: "Es cierto que no sabemos si los hombres son iguales. Estamos diciendo que pueden serlo. Esta es nuestra opinión, y estamos tratando, junto con los otros que piensan como nosotros, de verificarlo. Pero sabemos que este pueden serlo es lo que vuelve a la sociedad humana posible." (1991/2002, p. 107).

Recebido e aprovado em fevereiro de 2003.

\section{Nota}

1. Es interesante la observación de Rancière sobre el libro de enseñanza de la matemática según el método de enseñanza universal: "obra en la que, manteniendo el hábito frustrante del maestro, no hay una sóla palabra de matemática” (1991, 2002, p. 145-146). 
Confróntese esta observación con los tratados de didáctica especializada actuales. De qué hablarían si hubieran mantenido el mismo hábito?

\section{Referencias bibliográficas}

PANAGIA, D. Ceci n'est pas un argument: an introduction to the ten theses on politics. Theory and Event, Baltimore, v. 5, n. 3, p. 1-5, jul. 2001. Disponível em: <http://muse.jhu.edu/journals/theory_and_event/ v005/5.3panagia.html>

RANCIERE, J. The ignorant schoolmaster: five lessons in intellectual emancipation. Translated by Kristin Ross. Stanford, CA: Stanford University, 1991. (Em português: RANCIERE, J. O mestre ignorante. Belo Horizonte: Autêntica, 2002.). 